\title{
Modelling Multiple Sclerosis In Vitro and the Influence of Activated Macrophages
}

\author{
E.J.F. Vereyken, C.D. Dijkstra and C.E. Teunissen \\ VU University Medical Center \\ Amsterdam, \\ The Netherlands
}

\section{Introduction}

Multiple sclerosis (MS) is a chronic inflammatory disease of the central nervous system (CNS). The prevalence of MS is approximately 2 million people worldwide, with an incidence of about 1:1000 in Europe and Northern America, and women are affected more often compared to men, at a ratio of approximately 2:1. It is the most common cause of neurological disability among young adults with an onset generally between 20 and 40 years of age [Pugliatti et al., 2002]. The major neuropathological hallmarks of MS are demyelinating lesions associated with perivascular infiltrates, consisting of macrophages/microglia and lymphocytes. The lesions are characterized by destruction of myelin sheaths, oligodendrocyte death, axonal damage and glial scar formation, called astrogliosis. Demyelination is a central event in MS pathology. Although some remyelination occurs, it ultimately fails [Franklin, 2002]. The cause of the remyelination failure is not clear, although several processes have been suggested to play a role [Franklin and Ffrench-Constant, 2008; Wolswijk, 2002; John et al., 2002]. Not only processes behind remyelination failure remain elusive, also the cellular mechanisms behind the demyelination and axonal damage are largely unknown. Modelling MS both in animals and in vitro could help with understanding this.

This chapter will focus on MS pathology and the models that exist for investigating this disease, especially zooming in on in vitro models.

\section{Multiple sclerosis}

\subsection{Clinical symptoms and diagnosis}

MS is characterized by multiple sclerotic lesions affecting areas such as the cerebellum, cerebrum (periventricular white matter), optic nerve, brainstem and spinal cord [Compston and Coles, 2008]. The clinical symptoms of MS are very heterogeneous depending on the location, size and number of lesions. Symptoms include motor function disturbances, such as muscle weakness, tremor and paralysis, and progressive sensory malfunction, for instance impaired vision. The main criterion for diagnosis of MS is the occurrence of two (or more) independent episodes of clinical symptoms consistent with focal demyelination separated in space (part of the CNS) and time (more than one occasion) [Polman et al., 2011; McDonald et al., 2001]. Magnetic resonance imaging (MRI) techniques have become very important for verification of diagnosis [Barkhof et al., 1997; Nielsen et al., 2005; Polman et 
al., 2005], for detection of the number and size of the lesions and to differentiate between ongoing inflammation and blood-brain-barrier leakage [Bruck et al., 1997; Miller et al., 1998; Nesbit et al., 1991; Katz et al., 1993]. The presence of oligoclonal bands in cerebrospinal fluid (CSF) of MS patients and elevated immunoglobulin G (IgG) levels are supportive of MS diagnosis [Polman et al., 2011]. Furthermore, they corroborate the inflammatory demyelinating nature of the underlying condition, are used to evaluate alternative diagnoses and to predict clinical definite MS [Correale and de los Milagros Bassani Molinas, 2002]. In approximately $90 \%$ of MS patients oligoclonal immunoglobulin bands are detected [Bourahoui et al., 2004]. These oligoclonal bands are also detected in other neurological diseases, although not as consistently and persistently as in MS. In patients with clinically isolated syndrome the presence of oligoclonal bands is predictive for the progression to clinically definite MS [Paolino et al., 1996]. In MS patients the absence of oligoclonal bands is associated with a benign disease course, while high levels of oligoclonal bands are correlated with a severe disease, suggesting that oligoclonal bands may be clinically relevant [Correale and de los Milagros Bassani Molinas, 2002]. The identification of biomarkers for diagnosis and prognosis of MS is the subject of intense ongoing research [Teunissen et al., 2011; Ziemann et al., 2011; Junker et al., 2011; Teunissen et al., 2009]. One example is neurofilament light, which was found to be increased in clinically isolated syndrome patients, especially in those that converted to MS, and was observed to correlate with relapses and the number of gadolinium enhancing lesions [Teunissen et al., 2009].

Four major subtypes of MS with different progression and relapse characteristics have been recognized: the relapsing-remitting (RR-MS), the secondary-progressive (SP-MS), primary progressive (PP-MS) and progressive-relapsing (PR-MS) subtype [Lublin and Reingold, 1996]. Approximately $70 \%$ of the cases start with the RR subtype, which is characterized by clinical attacks that are followed by a clinically silent period with almost complete recovery. After a period of 15 to 20 years most cases of the RR-MS subtype develop progressive neurological deterioration without apparent remission, the SP-MS subtype. About $15-20 \%$ of MS patients show a progressive disease course without relapses and remissions from the beginning, the PP-MS subtype. Finally, less than 5\% suffer from PR-MS, characterized by progressive neurological impairment with occasional relapses.

\subsection{Pathology}

The major neuropathological hallmarks of MS are multiple focal inflammatory demyelinating lesions spread throughout the CNS. These lesions are associated with perivascular infiltrates containing macrophages and lymphocytes. Other features of MS plaques are axonal damage and loss, oligodendrocyte death and astrogliosis [Charcot, 1868], which is hypertrophy and an abnormal increase in the number of astrocytes. Lesions are classified based on the degree of myelin loss, the presence of inflammatory cells and HLADR expression on leukocytes and microglial cells. Four different stages in MS lesions have been identified: (p)reactive, active, chronic active and chronic inactive lesions [van der Valk and De Groot, 2000; de Groot et al., 2001].

In (p)reactive lesions no demyelination is apparent. Clusters of activated microglia can be observed with increased expression of HLA-DR expression and occasionally perivascular leukocyte infiltrations can be seen.

Active lesions are characterized by areas of demyelination containing macrophages, activated microglia and activated hypertrophic astrocytes. Activated astrocytes fill up the lesion area and form a gliotic scar. T-cells and some B-cells can be found, mostly in the 
perivascular space. The macrophages and microglia in the lesions contain myelin degradation products, such as myelin proteins and lipids, giving them a foamy appearance. The presence of myelin proteins in these macrophages reflect ongoing demyelination, since these myelin proteins are degraded in a known time frame [Bruck et al., 1995; van der Goes A. et al., 2005]. Oligodendrocyte death occurs in these lesions, often via apoptotic mechanisms [Wolswijk, 2000; Rodriguez and Lucchinetti, 1999]. This apoptosis of oligodendrocytes may be a disease initiating event, since it precedes leukocyte infiltration [Barnett and Prineas, 2004; Henderson et al., 2009].

Chronic active lesions are defined by a hypocellular demyelinated centre surrounded by a hypercellular rim with high numbers of foamy macrophages and reactive astrocytes. In these lesions oligodendrocyte numbers are reduced and lymphocytes are present in perivascular spaces.

In chronic inactive lesions almost no cellular infiltrates are present. They are hypocellular, demyelinated and contain widened extracellular spaces and gliotic scar tissue. In the CNS parenchyma and perivascular spaces relatively small numbers of macrophages and lymphocytes still remain. No myelin proteins can be detected in the macrophages.

Next to demyelination, remyelination also occurs [Franklin, 2002]. Remyelination can be restricted to the lesion edge, but can also extend throughout the lesions which are then called shadow-plaques [Bruck et al., 2003; Prineas et al., 1993; Prineas and Connell, 1979; Raine and Wu, 1993; Lassmann et al., 1997]. Oligodendrocyte precursor cells, after maturation into mature oligodendrocytes, generate thin myelin sheaths and could therefore contribute to recovery in MS patients. Remyelination in MS is limited. The cause of remyelination failure in MS is unknown, but several mechanisms have been proposed, such as restricted oligodendrocyte precursor cell migration, maturation and a growth inhibitory environment [Franklin, 2002; Wolswijk, 2002; John et al., 2002; Charles et al., 2002]. Macrophages could play an important role in remyelination as well [Doring and Yong, 2011].

It is clear from the above that macrophages are an important characteristic defining lesion stage. They likely play a central role in lesion formation in MS. In the next sections, we will describe the role of these immune cells in disease and particularly in MS in more detail.

\section{Macrophages in MS}

\subsection{Macrophages and innate immunity}

Macrophages (meaning "big eaters") are phagocytic cells that play a vital role in innate immunity, the first line of defense against pathogens. Cells of the innate immune system such as macrophages are able, to some extent, to discriminate between "self" and "nonself" antigens (reviewed by Janeway [Janeway, Jr. and Medzhitov, 2002]). Via a limited number of germline-encoded pattern recognition receptors, macrophages recognize highly conserved structures from bacteria, viruses and fungi. Several different families of pattern recognition receptors have been identified, for example macrophage scavenger receptors and the family of Toll-like receptors [Takeda and Akira, 2005; Akira et al., 2006]. After recognition, the binding of the receptor with its ligand on the pathogen, macrophages usually engulf the pathogen, a process called phagocytosis. This process results in the containment of microbes in the phagosome, which fuses with lysosomal vesicles containing a multitude of microbicidal products. Both oxygen-dependent, called the respiratory burst, and oxygen-independent microbicidal mechanisms exist. The 
respiratory burst uses an enzymatic complex called nicotinamide adenine dinucleotide phosphate reduced (NADPH) oxidase. Upon stimulation active NADPH oxidase forms. This active complex transfers two electrons from NADPH to two molecules of oxygen to form superoxide anion [DeLeo et al., 1999; Babior, 1999]. From this superoxide anion other ROS, such as hydrogen peroxide, are formed [Babior, 1999]. Oxygen-independent microbicidal mechanisms include acidification of the phagolysosome, nutrient depletion and antimicrobial proteins or peptides.

Macrophages differentiate from circulating monocytes. Once a monocyte migrates into a specific tissue, during steady-state or inflammation, it develops into a macrophage. Macrophages are present in virtually all tissues and usually specialize according to the tissue they are in, for instance osteoclasts (in bone), Kupffer cells (in liver) and microglia (in the CNS) [Gordon and Taylor, 2005].

Next to their role in innate immunity they have an important function in tissue homeostasis, since they are crucial for the clearance of apoptotic cells and the remodeling and repair of tissues after inflammation [Gordon, 1986; Gordon, 1998]. Phagocytosis of apoptotic cells does not induce the expression of inflammatory mediators in unstimulated macrophages [Kono and Rock, 2008].

During an infection macrophages also clear cellular debris of necrotic cells that contain endogenous danger signals, such as heat-shock proteins and nuclear proteins [Zhang and Mosser, 2008]. The detection of these danger signals alters the physiology of the macrophages, including expression of cell surface proteins, cytokines and pro-inflammatory mediators, increasing immune function of macrophages. However, macrophages can respond to many signals in the microenvironment of tissues and not all increase immune function.

\subsection{Macrophage activation results in different subtypes}

Macrophages are highly plastic cells and are able to respond to a variety of environmental cues changing their phenotype and physiology, resulting in different subtypes of macrophages. These different subtypes of macrophages have different functions in immune response, homeostasis and tissue repair [Gordon, 2003; Mosser, 2003; Mosser and Edwards, 2008].

Based on activation pathways several subtypes of macrophages have been described [Edwards et al., 2006b; Martinez et al., 2008]. The two most studied subtypes are: 1) the classically activated macrophages (CA, also called M1), induced by interferon-gamma (IFN- $\gamma$ ) and lipopolysaccharide (LPS); 2) the alternatively activated macrophages (AA, also called M2), stimulated by IL-4/13 and/or glucocorticoids. In 1992 Stein et al. introduced the concept of alternatively activated macrophages [Stein et al., 1992]. In contrast to the classically activated macrophages, macrophages stimulated with interleukin-4 (IL-4) increased the expression of mannose receptor (MR). Another study showed that Th1 cytokines (e.g. IFN- $\gamma$ ) and Th2 cytokines (e.g. IL-4) induced two distinct functional states in macrophages. Exposure of macrophages to Th2 cytokines led to an upregulation of certain phagocytic receptors and arginase, which reduced ability to kill intracellular pathogens, while Th1 cytokines led to induction of inducible nitric oxide synthase (iNOS) in macrophages [Modolell et al., 1995].

CA macrophages are cytotoxic and secrete high amounts of oxygen and nitrogen radicals in order to kill pathogens [Nathan and Shiloh, 2000]. CA macrophages also produce proinflammatory cytokines [O'Shea and Murray, 2008]. In mice, CA macrophages are 


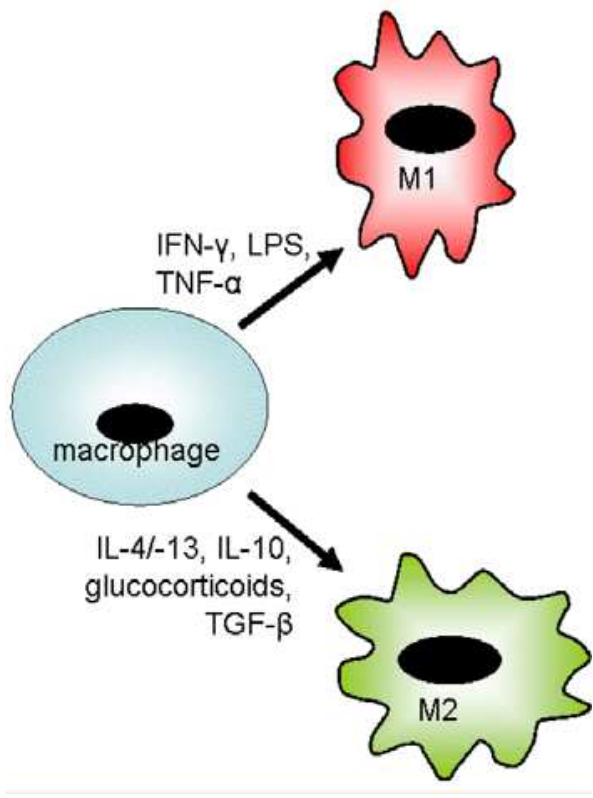

\begin{tabular}{|l|l|}
\hline & M1 macrophage \\
\hline Function & $\begin{array}{l}\text { Th1 response, microbicidal, } \\
\text { cytotoxic, tumour resistance }\end{array}$ \\
\hline Surface markers & $\begin{array}{l}\text { MHCII, CD86, CD80, CD40, } \\
\text { CD1 1b, FC } \gamma \text { RI, FC } \gamma \text { RI, CCR7 }\end{array}$ \\
\hline $\begin{array}{l}\text { Cytokines and } \\
\text { chemokines }\end{array}$ & $\begin{array}{l}\text { IL-1 } \beta, \text { IL-6, IL-8, IL-12, IL-23, } \\
\text { TNF- } \alpha \\
\text { CCL2, CCL5, CXCL9, CXCL10 }\end{array}$ \\
\hline $\begin{array}{l}\text { Extracellular } \\
\text { mediators }\end{array}$ & Release of superoxide and NO \\
\hline
\end{tabular}

\begin{tabular}{|l|l|}
\hline Function & M2 macrophage \\
\hline Surface markers & $\begin{array}{l}\text { Th2 response, allergy, parasite } \\
\text { response, tissue repair, } \\
\text { immunomodulatory }\end{array}$ \\
$\begin{array}{l}\text { MR (CD206), CD163, CD23, } \\
\text { CD36, MSR1, Dectin1, DCIR, } \\
\text { MARCO, CCR2, E-cadherin }\end{array}$ \\
\hline $\begin{array}{l}\text { Cytokines and } \\
\text { chemokines }\end{array}$ & $\begin{array}{l}\text { IL-1Ra, IL-10 } \\
\text { CCL13, CCL14, CCL16, CCL17, } \\
\text { CCL22 }\end{array}$ \\
\hline $\begin{array}{l}\text { Extracellular } \\
\text { mediators }\end{array}$ & $\begin{array}{l}\text { Fibronectin 1, IGF, PDGF-C, } \\
\text { TGF- } \beta \text {, FXIIIa, collagen IV }\end{array}$ \\
\hline
\end{tabular}

Fig. 1. Functions and characteristic markers of macrophage activation types. Macrophages can change their phenotype and function in response to signals from the environment. The most studied phenotypes are M1 and M2 macrophages. M1 macrophages are induced in vitro by IFN- $\gamma$, LPS and/or TNF- $\alpha$, while the induction of the M2 phenotype requires IL-4/13, IL-10, glucocorticoids or TGF- $\beta$

characterized by their production of nitric oxide (NO) [Edwards et al., 2006b; MacMicking et al., 1997; Hibbs, Jr., 2002]. Human macrophages derived from circulating monocytes do not generally produce NO [Mosser, 2003], therefore other markers should be used to discriminate between CA and AA macrophages, such as MR, E-cadherin [Van den Bossche J. et al., 2009], CD40 [Zeyda et al., 2007] and Fc-gamma receptor I (FcүRI). CA macrophages are essential for host defence [Gordon and Taylor, 2005; Nathan, 2008] and tumor killing. The pro-inflammatory mediators produced by CA macrophages can cause extensive damage to the host.

AA macrophages seem to play a role in immune suppression and tissue repair, due to production of anti-inflammatory cytokines and extracellular matrix components and lack of production of NO [Edwards et al., 2006b]. The most commonly used distinctive marker for AA macrophages, in mice, is the high expression and activity of arginase [Edwards et al., 2006b]. Due to the activation of arginase, arginine is converted to ornithine, a precursor for polyamines and collagen, which contributes to the production of extracellular matrix [Kreider et al., 2007; Albina et al., 1990; Gratchev et al., 2001; Hesse et al., 2001]. Furtermore, the polyamines produced can influence production of cytokines and suppress clonal expansion of lymphocytes, thereby regulating the immune response [Cordeiro-da-Silva et al., 2004]. 
Functional differences can be observed between CA and AA macrophages. As mentioned above, due to the production of ROS, CA macrophages are efficient in the killing of bacteria, while AA macrophages do not produce ROS and are therefore less efficient in killing bacteria [Gordon and Taylor, 2005]. Furthermore, CA macrophages are efficient antigen presenting cells, while AA macrophages are not [Edwards et al., 2006b]. CA macrophages are also more efficient in activating T-cell proliferation compared to AA macrophages [Edwards et al., 2006b]. AA macrophages are involved in scar formation, since they enhance fibrogenesis, while CA macrophages do not. AA macrophages stimulate proliferation and activation of fibroblasts, by expression and release of potent fibrogenic growth factors, like transforming growth factor-beta (TGF- $\beta$ ) and platelet derived growth factor (PDGF) [Song et al., 2000]. The angiogenic potential of AA macrophages is higher compared to CA macrophages [Kodelja et al., 1997]. Due to the production of growth factors and stimulation of angiogenesis, AA macrophages are considered tumor promoting. In vitro CA macrophages were shown to be cytotoxic to tumor cells but not to normal cells [RomieuMourez et al., 2006].

\subsection{Macrophages in MS lesion formation and repair}

It is widely accepted that macrophages play an important role in MS pathology. Macrophages are implicated in mechanisms that lead to demyelination and axonal damage [Bitsch et al., 2000; Kuhlmann et al., 2002; Trapp et al., 1998; Koning et al., 2007; Huitinga et al., 1990; Heppner et al., 2005; Hendriks et al., 2005; Newman et al., 2001]. Inflammatory infiltrates in MS lesions contain large amounts of macrophages. In experimental autoimmune encephalomyelitis (EAE), an animal model for MS, it has been shown that elimination of infiltrating macrophages reduced both clinical signs and axonal damage [Heppner et al., 2005]. Furthermore, during spinal cord injury (SCI), elimination of infiltrating macrophages increased axonal repair and functional outcome [Popovich et al., 1999; Stirling et al., 2004]. Clinical signs of EAE were significantly enhanced when the macrophage inhibitory signal of CD200/CD200R between neurons and macrophages was blocked [Koning et al., 2007]. This suggests a direct link between increased macrophage activity and aggravated disease course in EAE. Finally, macrophages are able to secrete a plethora of neurotoxic substances, such as matrix metalloproteinases [Newman et al., 2001], reactive oxygen species (ROS) [Nathan and Shiloh, 2000] and nitric oxide (NO) [Smith et al., 2001]. These studies all indicate that macrophages are detrimental.

However the role of macrophages is more complex. Several studies have shown that activated macrophages can actually be beneficial during CNS repair. During SCI macrophages can create a growth-permissive environment in which axonal regeneration can take place [Rapalino et al., 1998; Barrette et al., 2008]. In MS lesions, activated macrophages can be observed in areas with increased growth-associated protein-43 (GAP-43) expression [Teunissen et al., 2006]. In vitro AA macrophage conditioned medium has been found to promote axonal outgrowth [Kigerl et al., 2009]. Furthermore, macrophages are beneficial because they remove myelin debris, which is growth inhibiting for axons [Baer et al., 2009; Kotter et al., 2006], they release growth factors [Song et al., 2000; Kodelja et al., 1997] and they support axonal repair [Shechter et al., 2009; Bouhy et al., 2006; Batchelor et al., 2002]. These different roles ascribed to macrophages could be due to polarization in macrophage activation [Edwards et al., 2006a; Mosser and Edwards, 2008; Mantovani et al., 2004a] (Figure 1). 


\section{Models for MS}

\subsection{In vivo models}

Research on the mechanisms of demyelinating diseases is highly dependent on experimental animal models, due to the inaccessibility of the human brain for experimental research. Most frequently allergic autoimmune encephalitis (EAE) models are used as a model for MS. In EAE, an autoimmune reaction is induced by injection of myelin proteins or myelin-specific inflammatory T-cells into rats or mice. Disability starts with loss of tail tonus, leading to complete paralysis, which can be recovered. Demyelination occurs after a chronic induction paradigm. The model poses very serious discomfort to the many animals involved. Other animal models use viruses or chemical agents such as cuprizone or lysophosphatidylcholine (LPC) to induce demyelination [Ercolini and Miller, 2006; Matsushima and Morell, 2001; Woodruff and Franklin, 1999]. Another model that is currently increasingly used is the mutant shiverer mouse that carries a deletion in the myelin basic protein (MBP) gene [Nave, 1994]. Several drawbacks of using animal models are: i) per animal only one condition can be tested, making the use of many animals unavoidable, ii) investigating the mechanism behind demyelination at a cellular level is difficult, due to the complex interactions of the CNS with the immune system, iii) in vivo it is very difficult to control all experimental conditions.

\subsection{In vitro models}

Only few alternative in-vitro models for de- and remyelination are available. This is due to the complex interactions between axons, oligodendrocytes and astrocytes needed for the development of multilayered myelin around axons, which cannot be accomplished by cell lines or monolayer cultures. A demyelination model in slice cultures has been described using LPC [Birgbauer et al., 2004; Miron et al., 2010]. Slice cultures contain intact myelin of specific brain areas, and are therefore very suitable for experiments. A drawback, but also advantage, of the use of slice cultures is the fact that the cellular composition of the slice can not be altered. Furthermore, the top and bottom layer of the slice consists of damaged cells, which might influence the behavior of the layers underneath.

Another good and flexible in vitro model for the CNS is the culture of 3-dimensional brain spheroids. Spheroids are formed by continuous rotation of a single cell suspension of primary brain cells. These cells aggregate within 24 hours and start to differentiate. The result after 4 weeks of maturation is a spheroid containing all different brain cell types that make 3-dimensional contacts [Figure 2: 3-dimensional aspect of spheroid cultures]. The high level of differentiation is exemplified by the presence of myelinated axons and spontaneous synaptic activity. The model has been used for studying brain development, neurotoxicity, and neurodegenerative diseases [Berglund et al., 2004; Diemel et al., 2004; Honegger and Richelson, 1976].

In previous studies, immune-mediated demyelination has been induced in this model, using anti-myelin antibodies and complement [Diemel et al., 2004; Loughlin et al., 1994]. The major drawback of that model is that only modest and variable effects of antibodies were observed (personal observations C. Teunissen). We were able to induce non-inflammatory demyelination using LPC as well as subsequent recovery after LPC-withdrawal, in rodent brain spheroids. The effect of LPC was specific for myelin, since other CNS cell types present in the cultures were only slightly or not affected [Vereyken et al., 2009]. After 
cessation of LPC treatment, remyelination was observed in these culture (Figure 3) . These data demonstrate the potential of this model to study several fundamental aspects of deand remyelination.
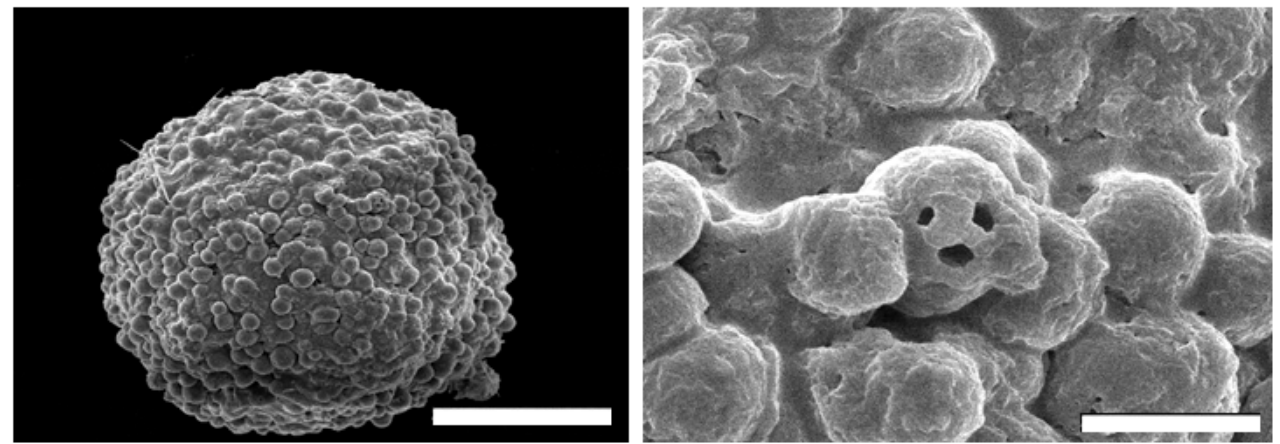

Copyright permission has been obtained from Brain Research.

(A)

Fig. 2. Scanning electron microscopy photograph of a cultured spheroid. (A) Example of 3-week-old whole brain spheroids showing a typical three-dimensional appearance. Bar represents $50 \mathrm{~mm}$. (B) Higher magnification than (A), bar represents $5 \mathrm{~mm}$. Teunissen et al 2000 [Teunissen et al., 2000]

\section{Macrophage-CNS interaction in an in vitro model for MS}

Microglia are present in spheroids, and these can be activated to study the effects of macrophages on myelin formation and demyelination. Alternatively, activated macrophages can be supplemented to the cultures. We set out to study whether the spheroid culture model is suitable for studying effects of supplemented macrophages. An important first question was whether macrophages are able to migrate into the spheroids, which would be a benefit of this model over in vivo models as there is no blood brain barrier (BBB) and the influence of BBB interruption can be circumvented. Next, we were especially interested to determine the effects of macrophages on CNS cell types inside the spheroids. Our hypothesis was that CA macrophages would have toxic effects and AA macrophages positive effects on myelin, glia and axonal integrity. No studies so far have addressed the question if these differential macrophage phenotypes have differential effects on intact CNS tissue. Therefore, we also set out to compare the effects of CA and AA macrophages on cellular structures within whole brain spheroid cultures.

\subsection{Number of macrophages in spheroids}

First, we established whether macrophages could migrate into the spheroids, and whether the numbers were similar for the CA and AA macrophage phenotypes. For this, we cultured rat whole brain spheroids during 4 weeks, to reach optimal myelin development, and exposed them to differently activated macrophages, that were fluorescently labeled, [method of macrophage activation: Vereyken et al., 2011] during maximal 1 week. At several time points, cryostat sections were cut of the spheroids and the number of spheroids containing macrophages were counted. 

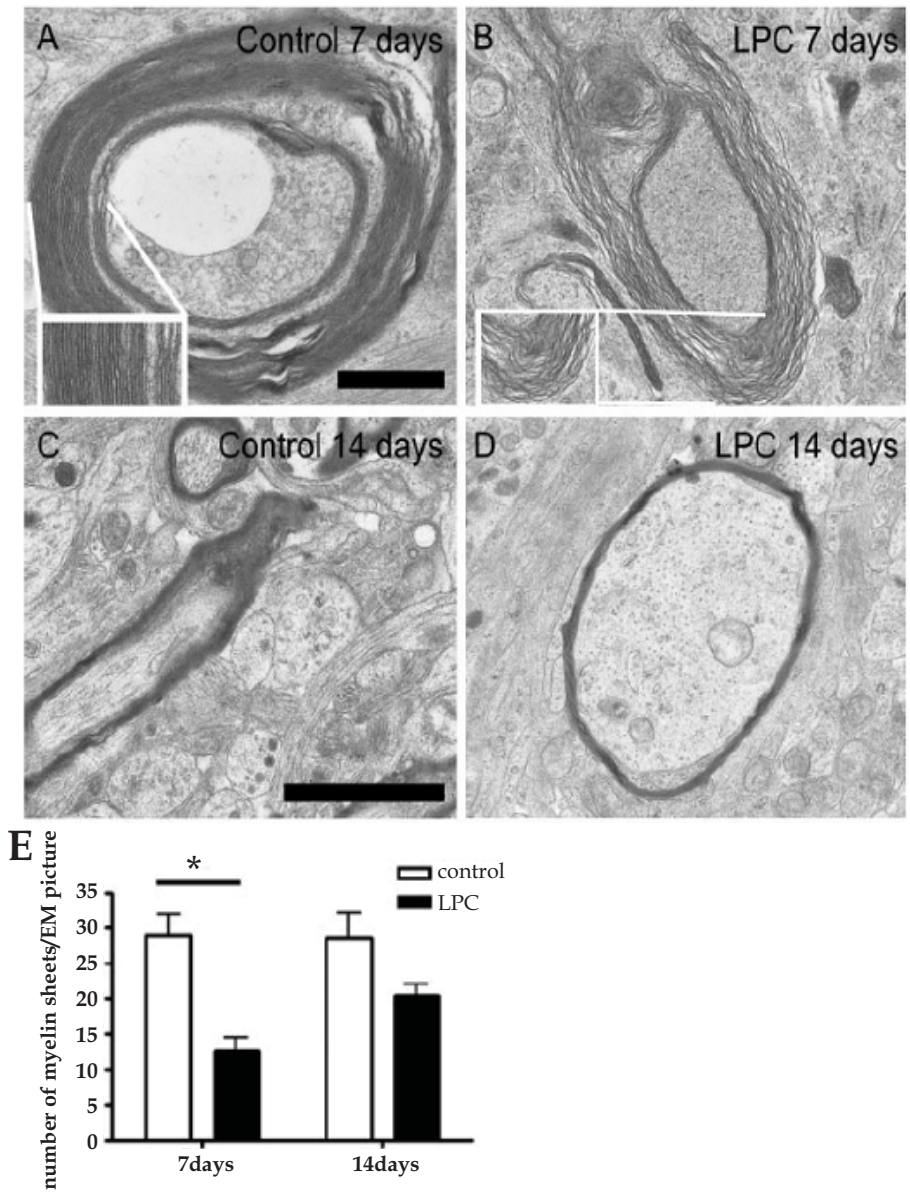

Copyright permission obtained from Brain Research and also from Glia

Fig. 3. EM picture of demyelinated rat whole brain spheroid cultures. A: After 4 weeks of culturing the experiment was started at day 0 . After 7 days ( 5 weeks of culturing) multilayered compact myelin was present. See insert for more detail. B: After a week of exposure to LPC (three times addition of $0.12 \mathrm{mM} \mathrm{LPC}$ ), at day 7 (= week 5 of culturing), the myelin layers were loosely packed. See insert for more detail. C: Control cultures at day 14 (6 week old cultures), show compact myelin. D: At day 14, after 1 week of exposure to LPC and 1 week of recovery, LPC-exposed cultures show compact myelin. Bar is $500 \mathrm{~nm}$. E: Quantification of the number of myelin sheets present in EM pictures from two separate experiments (four pictures from three spheroids). After LPC treatment at 7 days 12.5 myelin sheets per picture were counted. When compared with control spheroids, 29 myelin sheets per picture, a significant decrease of $56 \%$ was, therefore, visible. At 14 days, the number of myelin sheets was not significantly different between control, 28 myelin sheets per picture, and LPC treated, 20 myelin sheets per picture, cultures. Results are presented as mean \pm SEM. Open bars: control; closed bars: LPC treated; asterisks indicate $\mathrm{P}<0.05$. [Vereyken et al.. 2009] 
We observed a temporal pattern. After 1 day no macrophages were visible in the spheroids (data not shown). At 2 days after macrophage addition, low numbers of macrophages were present in spheroids exposed to AA and unstimulated (US) macrophages (data not shown). At 3 days macrophages were observed in $40-70 \%$ of the spheroid sections (Figure $4 \mathrm{~A}$ and D). After 8 days the macrophage numbers were decreased compared to day 3 (data not shown). Most macrophages were associated with spheroids on the outside rim of the spheroid, but several also migrated into the center of the spheroids (Figure 4A, B, C). A larger number of spheroids contained one or more macrophages when exposed to either AA or US macrophages compared to CA macrophages (Figure 4D). These results were in agreement with our previous observations showing that AA macrophages have a higher intrinsic motility compared to CA macrophages [Vereyken et al., 2011]. Furthermore, CA macrophages had been observed to express higher levels of adhesion receptors compared to both AA and US macrophages [Vereyken et al., 2011]. Thus, the lower motility and higher adhesion could contribute to the lower migration of CA macrophages into spheroids.

After induction of demyelination, a similar pattern was observed for the differentially activated macrophages, i.e. a higher percentage of spheroids contained AA and US macrophages (Figure 4E). Taken together, all different macrophage phenotypes could migrate into the spheroids, while the extend of migration differed between phenotypes.

\subsection{Effect of differentially activated macrophages on CNS cells in spheroid cultures}

Next, we tested whether CA and AA macrophages had and effect on CNS cells in the spheroids and whether the effects were dependent on the macrophage phenotype. We quantified the total immunoreactivity per spheroid section using image analysis software [Vereyken et al., 2009]. Figure 5A-D. show the results of the quantification of the immunereactivity (IR). MBP immunereactivity was 50\% increased in spheroid cultures exposed to CA and AA macrophages, compared to control spheroid cultures (spheroids exposed to unstimulated macrophages and spheroid cultures without macrophages). Figure 6A-D shows representative images of MBP staining after exposure of intact spheroids to differently activated macrophages. In control spheroids, MBP IR was present in structures in the center and at the borders (Figure 6A). In the spheroids exposed to unstimulated macrophages a similar picture was observed, although, in some spheroids a higher number of MBP-positive structures near the border was observed (Figure 6B). Note that in this specific section, no intact macrophages are visible, which is likely due to the relatively low numbers of macrophages inside the spheroids in combination with the low thickness of the sections. After exposure to CA macrophages, a higher mean IR was observed at the spheroid border (Figure 6C). The mean IR was also increased in spheroids exposed to AA macrophages (Figure 6D). This increase was mainly observed in the area just below the border.

GFAP IR was not affected by addition of the macrophages. GFAP IR was slightly lower in spheroids exposed to AA macrophages compared to spheroids exposed to CA macrophages (Fig 5B). $\beta$-tubulin IR was decreased by $50 \%$ in CA macrophage-exposed spheroids compared to control spheroids, not exposed to any macrophages. Tubulin staining was present in center of the control spheroids, as described before [Vereyken et al., 2009]. After exposure of the spheroids to CA macrophages especially the $\beta$-tubulin IR in the center of the spheroids was decreased (Figure 5C). A slight increase in GAP-43 IR was observed in spheroids exposed to CA macrophages compared to control spheroids not exposed to macrophages (Figure 5D). 

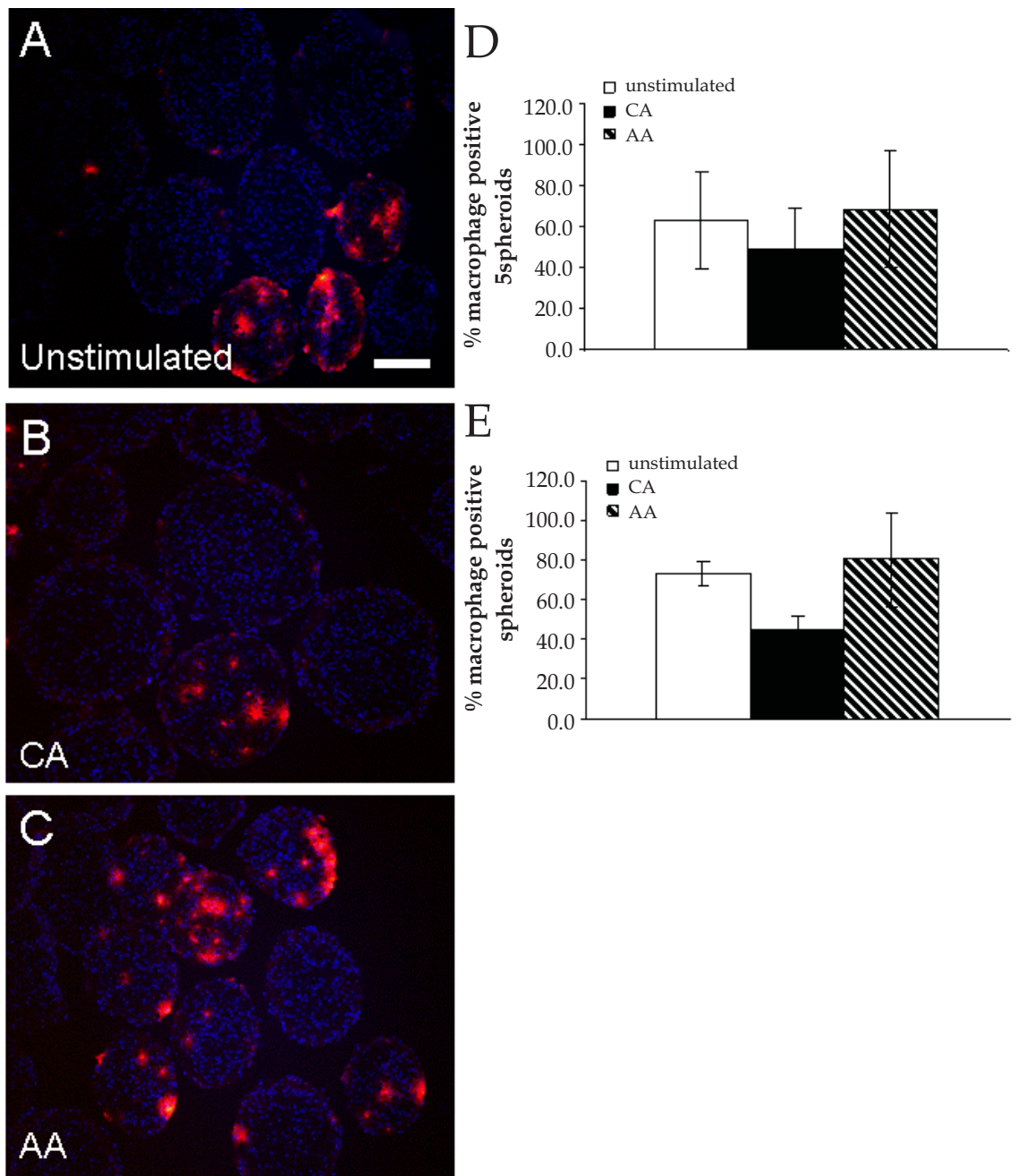

Fig. 4. Migration of macrophages in whole brain spheroid cultures. Mature spheroids were exposed to unstimulated (A); classically activated (CA); of alternatively activated (AA) macrophages during three days. Macrophages were labelled with DiI before addition to the cultures. Sections were prepared and nuclei stained with Hoechst. Bar in A is $200 \mu \mathrm{m}$. Figure 4D and E: Quantification of migration of differently activated macrophages in whole brain spheroids. D: The number of positive spheroids was determined as the number of spheroids containing one or more macrophages/total number of control spheroids. A trend could be seen of a lower migration of CA macrophages into spheroids compared to unstimulated and AA macrophages. E: Quantification of migration of macrophages is higher in demyelinated spheroids. Unstimulated macrophages were present in $73 \%( \pm 6)$ of the LPC-demyelineated spheroids. Spheroids exposed to CA macrophages. Only $45 \%( \pm 6)$ of the LPC-demyelineated spheroids were positive for CA macrophages. With AA macrophages the percentage of spheroids positive was $80 \%( \pm 24)$ 
A
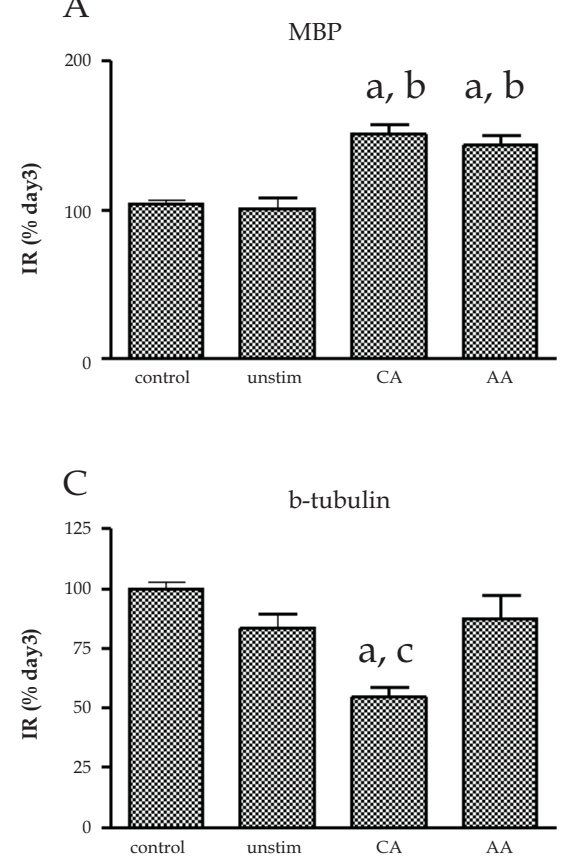

B
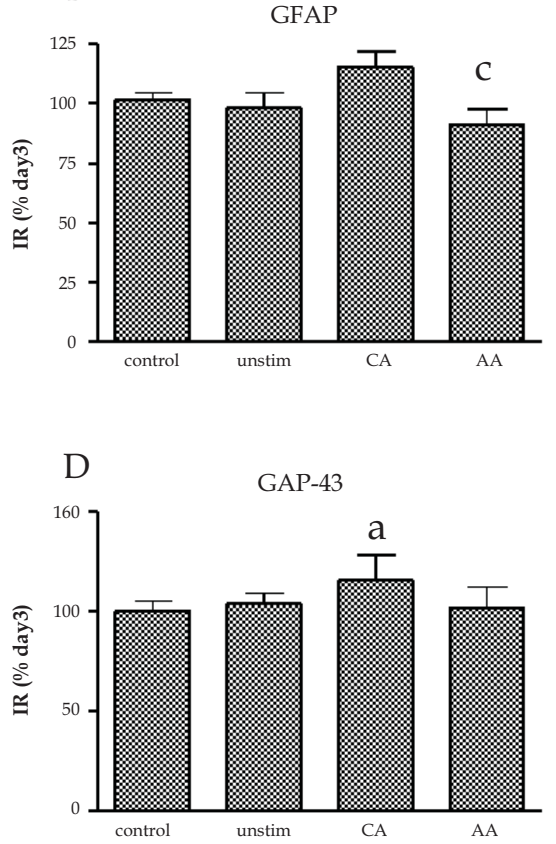

Fig. 5. Quantification of effects of differentially activated macrophages on immunereactivity of specific CNS cell proteins in spheroid cultures. Unstim=unstimulated macrophages; CA: classically activated macrophages; AA: Alternatively activated macrophages. Fourweeks old whole brain spheroid cultures exposed to unstim, CA or AA macrophages during 3 days. a: $\mathrm{P}<0.05$ compared to control; $\mathrm{b}: \mathrm{P}<0.05$ compared to unstimulated macrophages; c: $\mathrm{P}<0.05$ for differences between $\mathrm{CA}$ and AA macrophages

\subsection{Discussion of the experimental results in spheroid cultures}

The first aim of the experiments described above was to study whether macrophages can migrate into the spheroid cultures. This was indeed the case. Externally supplemented macrophages can be labeled to trace them within the spheroid and we observed that they can migrate into the center of the spheroid.

The second aim was to study effects of classically and alternatively activated macrophages on cellular structures of whole brain spheroid cultures. Our hypothesis was that CA macrophages would have toxic effects and that AA macrophages have positive effects on myelin and axonal integrity. Our results were in part supportive for this hypothesis: CA macrophages had a slight negative effect on tubulin immune reactivity in intact spheroids, while AA macrophages had no effect on tubulin immune reactivity. This indicates that CA macrophages were toxic to neurons, while AA macrophages were not. These data are in agreement with our observations in monolayers (EJFV Unpublished observation). The GFAP immunereactivity was slightly higher in CA exposed macrophages compared to AA exposed macrophages. However, for many of our read-outs there were no substantial differences between the differently activated macrophages. A similar positive effect of both 

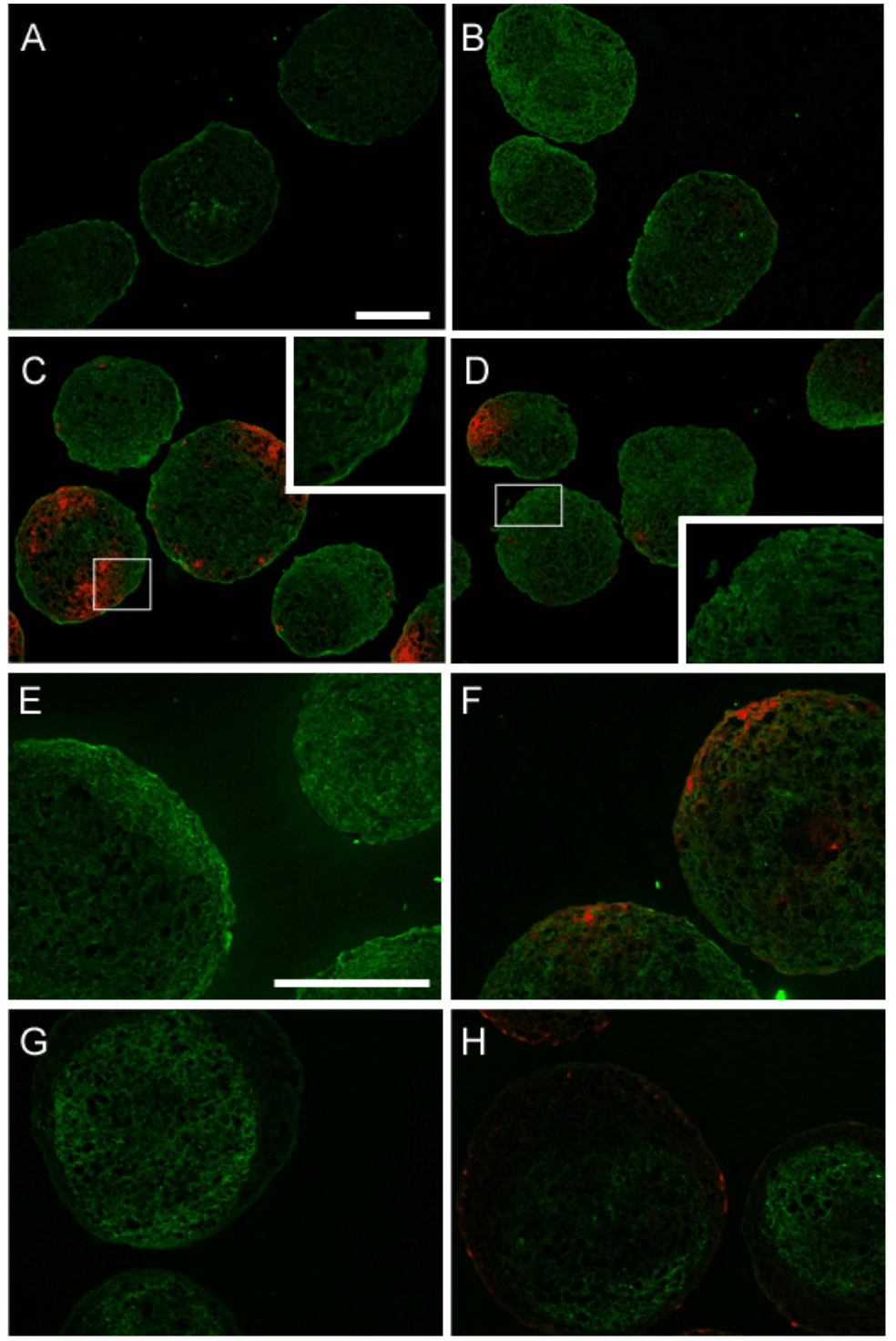

Fig. 6. Effects of differentially activated macrophages on immunereactivity of myelin basic protein (MBP) in spheroid cultures. Four-weeks old whole brain spheroid cultures were exposed to unstim, CA or AA macrophages during 3 days. A: MBP immune reactivity in control spheroids without exposure to macrophages.; B-D: MBP immune reactivity in spheroids exposed to (B) unstimulated macrophages, (C) classically activated (CA) macrophages, and (D) Alternatively activated macrophages (AA). E: GFAP IR in spheroids exposed to CA macrophages; F: GFAP IR in spheroids exposed to AA macrophages.

G: $\beta$-tubulin IR in control spheroids. H: $\beta$-tubulin IR in spheroids exposed to CA macrophages. Bar in $\mathrm{A}$ and $\mathrm{G}=200 \mu \mathrm{m}$ 
CA and AA macrophages on MBP immunereactivity in spheroids was observed. The lack of large differences between the different macrophage phenotypes could be related to the length of the experiments and the flexibility of the macrophage phenotypes, as a fundamental characteristic of macrophages is their ability to change their phenotype and they could all have a similar phenotype after a few days of contact with the CNS tissue. However, the duration of the experiments was three days, and we observed differences in migration between the phenotypes after 3 days. The different phenotypes do contain similar receptors, and it is possible that MBP expression is influenced by growth factors that may be differently, but at least sufficient on both phenotypes for induction of the observed.

Taken together, our results have shown that CA and AA macrophages can both affect myelin formation in spheroid cultures. Future studies must show whether macrophages can enhance myelin formation after demyelination and the conditions under which they can have regenerative effects.

\section{Future perspectives}

There are various in vivo and in vitro models for de- and remyelination in MS. The use of each of the models will depend on the research question. In vitro models provide the possibility to study direct effects on CNS cell types, without interference of other processes. Furthermore, access to CNS cell types is not hampered by the blood brain barrier. Furthermore, use of in in vitro models leads to a reduction of animal suffering. Nevertheless, we do not expect in vitro results to be directly translatable to the human situation and thus an intermediate step in vivo will be needed, but this can be on a limited scale when the range of conditions are narrowed by in vitro experiments.

In MS lesions, macrophages with the CA phenotype could inhibit repair or propagate lesion formation, since CA macrophages have been shown to be neurotoxic while AA activation abolished the neurotoxic effects. In MS lesions it could therefore be beneficial to reduce the CA phenotype and promote the AA phenotype. Possible mechanisms to skew the macrophage phenotype in the CNS are interesting to investigate, in order to design antiinflammatory therapies. Here, we discuss these options.

\subsection{Skewing of macrophage phenotype}

Glucocorticoids are an accepted therapy during MS. Treatment with glucocorticoids might be a means of skewing the activational phenotype, since exposure to glucocorticoids induce a wound healing phenotype in macrophages in vitro [Mosser and Edwards, 2008; Gordon, 2003]. A glucocorticoid receptor ligand was found to attenuate experimental autoimmune neuritis, decrease the expression of inflammatory cytokines and iNOS and induce a M2 phenotype in vitro [Zhang et al., 2009].

Evidence for the possibility that substances in the periphery can influence CNS cells has been observed previously. In the CNS microglia have been shown to switch cytokine profile, from relatively anti-inflammatory to pro-inflammatory CA phenotype, after induction of Wallerian degeneration followed by systemic injection of LPS [Palin et al., 2008]. The peripheral LPS injection also led to a decrease in neurofilament staining, indicating that neurodegeneration is increased. Similar results were found with a mouse model for prion disease, more inflammation and neuronal apoptosis after systemic LPS injection [Cunningham et al., 2005]. Likewise, glucocorticoids and glatiramer acetate, when applied peripherally, could influence the phenotype of microglia and macrophages inside the CNS. 
It would therefore be interesting to determine the effect of glucocorticoid treatment on the macrophage phenotype in the CNS. Furthermore, since in MS lesions the macrophages predominantly express markers of the CA phenotype, it would be useful to study whether AA macrophages that enter a pro-inflammatory environment would be able to keep their phenotype. Could AA macrophages be able to exert positive effects in a pro-inflammatory environment? These questions can be investigated using in vitro models, such as the spheroid model, representing the CNS environment.

\subsection{Injection of skewed macrophages}

Some investigation into direct treatment with AA macrophages has been performed and therapeutic effects have been observed. In a model for murine diabetes a reduction in renal and pancreatic injury was seen after treatment with in vitro generated AA macrophages [Zheng et al., 2011]. The injection of AA macrophages reduced disease in a model for colitis [Hunter et al., 2010]. Furthermore, axonal dieback induced by macrophages was reduced after the addition of multipotent adult progenitor cells, which induced the AA phenotype in macrophages in vitro [Busch et al., 2011]. During EAE, treatment with substances skewing the macrophage phenotype toward an AA phenotype, such as anti-CCL22 [Dogan et al., 2011] and 2-arachidonoylglycerol [Lourbopoulos et al., 2011], was found to ameliorate the disease course and increase the presence of macrophages with an AA phenotype in the lesions. In a model for relapsing EAE, the injection of AA macrophages, generated in vitro, reduced the development of relapses [Mikita et al., 2011]. Clinical EAE was reversed by the adoptive transfer of AA macrophages, which were induced in vitro with glatiramer acetate [Weber et al., 2007]. Our studies have shown that macrophage migration towards CNS cell types differs upon skewing [Vereyken et al., 2011] and that migration of macrophages in spheroids is limited and varies with skewing of the macrophages (Figure 4E). Microinjection of skewed macrophages into spheroids or co-culture of differently activated macrophages would allow more in depth analysis into the cellular mechanisms behind the effects reported in these studies.

\section{Conclusion}

Spheroid cultures are a suitable model to test the effects of novel therapeutics on remyelination, e.g. magnitude and speed. Furthermore, this model is very useful to study the mechanism of remyelination and the effects of demyelination, for example on axons. Using spheroid cultures, cells not endogenous to the CNS, like macrophages, can be introduced into the spheroids with relative ease [Loughlin et al., 1994; Loughlin et al., 1997; Pardo and Honegger, 2000] as we demonstrated. Both CA and AA macrophages can have beneficial effects in an MS lesion. The CA macrophages are very efficient in clearing debris, however, they are toxic to neurons. The AA macrophages secrete higher amounts of neurotrophins and are not neurotoxic, however they are less efficient in clearing debris. It would be of great value if an activational status in macrophages could be reached with an increased phagocytic capacity, without the production of neurotoxic substances such as ROS, NO and TNF- $\alpha$, and with the secretion of growth factors. Future research should therefore focus on the functional activation status of macrophages stimulated with for example glucocorticoids, to enhance the secretion of growth factors and phagocytosis and limit secretion of neurotoxic substances. 


\section{Acknowledgements}

We would like to extend our gratitude towards all who have contributed to the spheroid studies: Marije Bolijn, Priscilla Heijnen, Wia Baron, Sjef Copray, Elga de Vries, Amos Attali and Ilja Boor. Support grant: Dutch MS Research Foundation, grant number: 05-358c. Dutch Research Council (NWO (016.056.024))

\section{References}

Akira S, Uematsu S, Takeuchi O (2006) Pathogen recognition and innate immunity. Cell 124: 783-801

Albina JE, Mills CD, Henry WL, Jr., Caldwell MD (1990) Temporal expression of different pathways of 1-arginine metabolism in healing wounds. J Immunol 144: 3877-3880

Babior BM (1999) NADPH oxidase: an update. Blood 93: 1464-1476

Baer AS, Syed YA, Kang SU, Mitteregger D, Vig R, Ffrench-Constant C, Franklin RJ, Altmann F, Lubec G, Kotter MR (2009) Myelin-mediated inhibition of oligodendrocyte precursor differentiation can be overcome by pharmacological modulation of Fyn-RhoA and protein kinase $C$ signalling. Brain 132: 465-481

Barkhof F, Filippi M, Miller DH, Scheltens P, Campi A, Polman CH, Comi G, Ader HJ, Losseff N, Valk J (1997) Comparison of MRI criteria at first presentation to predict conversion to clinically definite multiple sclerosis. Brain 120 ( Pt 11): 2059-2069

Barnett MH, Prineas JW (2004) Relapsing and remitting multiple sclerosis: pathology of the newly forming lesion. Ann Neurol 55: 458-468

Barrette B, Hebert MA, Filali M, Lafortune K, Vallieres N, Gowing G, Julien JP, Lacroix S (2008) Requirement of myeloid cells for axon regeneration 1. J Neurosci 28: 93639376

Batchelor PE, Porritt MJ, Martinello P, Parish CL, Liberatore GT, Donnan GA, Howells DW (2002) Macrophages and Microglia Produce Local Trophic Gradients That Stimulate Axonal Sprouting Toward but Not beyond the Wound Edge 1. Mol Cell Neurosci 21: 436-453

Berglund CM, Aarum J, Haeberlein SL, Nyengaard JR, Hokfelt T, Sandberg K, Naslund J, Persson MA (2004) Characterization of long-term mouse brain aggregating cultures: evidence for maintenance of neural precursor cells. J Comp Neurol 474: 246260

Birgbauer E, Rao TS, Webb M (2004) Lysolecithin induces demyelination in vitro in a cerebellar slice culture system. J Neurosci Res 78: 157-166

Bitsch A, Schuchardt J, Bunkowski S, Kuhlmann T, Bruck W (2000) Acute axonal injury in multiple sclerosis. Correlation with demyelination and inflammation. Brain 123 ( Pt 6): 1174-1183

Bouhy D, Malgrange B, Multon S, Poirrier AL, Scholtes F, Schoenen J, Franzen R (2006) Delayed GM-CSF treatment stimulates axonal regeneration and functional recovery in paraplegic rats via an increased BDNF expression by endogenous macrophages. FASEB J 20: 1239-1241

Bourahoui A, De SJ, Guttierez R, Onraed B, Hennache B, Ferriby D, Stojkovic T, Vermersch $P$ (2004) CSF isoelectrofocusing in a large cohort of MS and other neurological diseases. Eur J Neurol 11: 525-529

Bruck W, Bitsch A, Kolenda H, Bruck Y, Stiefel M, Lassmann H (1997) Inflammatory central nervous system demyelination: correlation of magnetic resonance imaging findings with lesion pathology. Ann Neurol 42: 783-793 
Bruck W, Kuhlmann T, Stadelmann C (2003) Remyelination in multiple sclerosis. J Neurol Sci 206: 181-185

Bruck W, Porada P, Poser S, Rieckmann P, Hanefeld F, Kretzschmar HA, Lassmann H (1995) Monocyte/macrophage differentiation in early multiple sclerosis lesions. Ann Neurol 38: 788-796

Busch SA, Hamilton JA, Horn KP, Cuascut FX, Cutrone R, Lehman N, Deans RJ, Ting AE, Mays RW, Silver J (2011) Multipotent adult progenitor cells prevent macrophagemediated axonal dieback and promote regrowth after spinal cord injury. J Neurosci 31: 944-953

Charcot M (1868) Histolgie de le sclerose en plaques. Gaz Hop 141: 554-558

Charles P, Reynolds R, Seilhean D, Rougon G, Aigrot MS, Niezgoda A, Zalc B, Lubetzki C (2002) Re-expression of PSA-NCAM by demyelinated axons: an inhibitor of remyelination in multiple sclerosis? Brain 125: 1972-1979

Compston A, Coles A (2008) Multiple sclerosis. Lancet 372: 1502-1517

Cordeiro-da-Silva A, Tavares J, Araujo N, Cerqueira F, Tomas A, Kong Thoo LP, Ouaissi A (2004) Immunological alterations induced by polyamine derivatives on murine splenocytes and human mononuclear cells. Int Immunopharmacol 4: 547-556

Correale J, de los Milagros Bassani Molinas (2002) Oligoclonal bands and antibody responses in multiple sclerosis. J Neurol 249: 375-389

Cunningham C, Wilcockson DC, Campion S, Lunnon K, Perry VH (2005) Central and systemic endotoxin challenges exacerbate the local inflammatory response and increase neuronal death during chronic neurodegeneration. J Neurosci 25: 9275-9284

de Groot CJ, Bergers E, Kamphorst W, Ravid R, Polman CH, Barkhof F, Van der Valk P. (2001) Post-mortem MRI-guided sampling of multiple sclerosis brain lesions: increased yield of active demyelinating and (p)reactive lesions. Brain 124: 1635-1645

DeLeo FR, Allen LA, Apicella M, Nauseef WM (1999) NADPH oxidase activation and assembly during phagocytosis. J Immunol 163: 6732-6740

Diemel LT, Wolswijk G, Jackson SJ, Cuzner ML (2004) Remyelination of cytokine- or antibody-demyelinated CNS aggregate cultures is inhibited by macrophage supplementation. Glia 45: 278-286

Dogan RN, Long N, Forde E, Dennis K, Kohm AP, Miller SD, Karpus WJ (2011) CCL22 regulates experimental autoimmune encephalomyelitis by controlling inflammatory macrophage accumulation and effector function. J Leukoc Biol 89: 93104

Doring A, Yong VW (2011) The good, the bad and the ugly. Macrophages/microglia with a focus on myelin repair. Front Biosci (Schol Ed) 3: 846-856

Edwards JP, Zhang X, Frauwirth KA, Mosser DM (2006b) Biochemical and functional characterization of three activated macrophage populations. J Leukoc Biol 80: 12981307

Edwards JP, Zhang X, Frauwirth KA, Mosser DM (2006a) Biochemical and functional characterization of three activated macrophage populations. J Leukoc Biol 80: 12981307

Ercolini AM, Miller SD (2006) Mechanisms of immunopathology in murine models of central nervous system demyelinating disease. J Immunol 176: 3293-3298

Franklin RJ (2002) Why does remyelination fail in multiple sclerosis? Nat Rev Neurosci 3: 705714

Franklin RJ, Ffrench-Constant C (2008) Remyelination in the CNS: from biology to therapy. Nat Rev Neurosci 9: 839-855

Gordon S (1986) Biology of the macrophage. J Cell Sci Suppl 4: 267-286 
Gordon S (1998) The role of the macrophage in immune regulation. Res Immunol 149: 685-688

Gordon S (2003) Alternative activation of macrophages. Nat Rev Immunol 3: 23-35

Gordon S, Taylor PR (2005) Monocyte and macrophage heterogeneity. Nat Rev Immunol 5: 953-964

Gratchev A, Guillot P, Hakiy N, Politz O, Orfanos CE, Schledzewski K, Goerdt S (2001) Alternatively activated macrophages differentially express fibronectin and its splice variants and the extracellular matrix protein betaIG-H3. Scand J Immunol 53: 386-392

Henderson AP, Barnett MH, Parratt JD, Prineas JW (2009) Multiple sclerosis: distribution of inflammatory cells in newly forming lesions. Ann Neurol 66: 739-753

Hendriks JJ, Teunissen CE, de Vries HE, Dijkstra CD (2005) Macrophages and neurodegeneration. Brain Res Brain Res Rev 48: 185-195

Heppner FL, Greter M, Marino D, Falsig J, Raivich G, Hovelmeyer N, Waisman A, Rulicke T, Prinz M, Priller J, Becher B, Aguzzi A (2005) Experimental autoimmune encephalomyelitis repressed by microglial paralysis. Nat Med 11: 146-152

Hesse M, Modolell M, La Flamme AC, Schito M, Fuentes JM, Cheever AW, Pearce EJ, Wynn TA (2001) Differential regulation of nitric oxide synthase- 2 and arginase- 1 by type 1 /type 2 cytokines in vivo: granulomatous pathology is shaped by the pattern of L-arginine metabolism. J Immunol 167: 6533-6544

Hibbs JB, Jr. (2002) Infection and nitric oxide. J Infect Dis 185 Suppl 1: S9-17

Honegger P, Richelson E (1976) Biochemical differentiation of mechanically dissociated mammalian brain in aggregating cell culture. Brain Res 109: 335-354

Huitinga I, Van Rooijen N, De Groot CJ, Uitdehaag BM, Dijkstra CD (1990) Suppression of experimental allergic encephalomyelitis in Lewis rats after elimination of macrophages. J Exp Med 172: 1025-1033

Hunter MM, Wang A, Parhar KS, Johnston MJ, van RN, Beck PL, McKay DM (2010) In vitroderived alternatively activated macrophages reduce colonic inflammation in mice. Gastroenterology 138: 1395-1405

Janeway CA, Jr., Medzhitov R (2002) Innate immune recognition. Annu Rev Immunol 20: 197216

John GR, Shankar SL, Shafit-Zagardo B, Massimi A, Lee SC, Raine CS, Brosnan CF (2002) Multiple sclerosis: re-expression of a developmental pathway that restricts oligodendrocyte maturation. Nat Med 8: 1115-1121

Junker A, Hohlfeld R, Meinl E (2011) The emerging role of microRNAs in multiple sclerosis. Nat Rev Neurol 7: 56-59

Katz D, Taubenberger JK, Cannella B, McFarlin DE, Raine CS, McFarland HF (1993) Correlation between magnetic resonance imaging findings and lesion development in chronic, active multiple sclerosis. Ann Neurol 34: 661-669

Kigerl KA, Gensel JC, Ankeny DP, Alexander JK, Donnelly DJ, Popovich PG (2009) Identification of two distinct macrophage subsets with divergent effects causing either neurotoxicity or regeneration in the injured mouse spinal cord. J Neurosci 29: 13435-13444

Kodelja V, Muller C, Tenorio S, Schebesch C, Orfanos CE, Goerdt S (1997) Differences in angiogenic potential of classically vs alternatively activated macrophages. Immunobiology 197: 478-493

Koning N, Bo L, Hoek RM, Huitinga I (2007) Downregulation of macrophage inhibitory molecules in multiple sclerosis lesions. Ann Neurol 62: 504-514

Kono H, Rock KL (2008) How dying cells alert the immune system to danger. Nat Rev Immunol 8: 279-289 
Kotter MR, Li WW, Zhao C, Franklin RJ (2006) Myelin impairs CNS remyelination by inhibiting oligodendrocyte precursor cell differentiation. J Neurosci 26: 328-332

Kreider T, Anthony RM, Urban JF, Jr., Gause WC (2007) Alternatively activated macrophages in helminth infections. Curr Opin Immunol 19: 448-453

Kuhlmann T, Lingfeld G, Bitsch A, Schuchardt J, Bruck W (2002) Acute axonal damage in multiple sclerosis is most extensive in early disease stages and decreases over time. Brain 125: 2202-2212

Lassmann H, Bruck W, Lucchinetti C, Rodriguez M (1997) Remyelination in multiple sclerosis. Mult Scler 3: 133-136

Loughlin AJ, Copelman CA, Hall A, Armer T, Young BC, Landon DN, Cuzner ML (1997) Myelination and remyelination of aggregate rat brain cell cultures enriched with macrophages. J Neurosci Res 47: 384-392

Loughlin AJ, Honegger P, Woodroofe MN, Comte V, Matthieu JM, Cuzner ML (1994) Myelin basic protein content of aggregating rat brain cell cultures treated with cytokines and/or demyelinating antibody: effects of macrophage enrichment. $J$ Neurosci Res 37: 647-653

Lourbopoulos A, Grigoriadis N, Lagoudaki R, Touloumi O, Polyzoidou E, Mavromatis I, Tascos N, Breuer A, Ovadia H, Karussis D, Shohami E, Mechoulam R, Simeonidou C (2011) Administration of 2-arachidonoylglycerol ameliorates both acute and chronic experimental autoimmune encephalomyelitis. Brain Res 1390: 126-141

Lublin FD, Reingold SC (1996) Defining the clinical course of multiple sclerosis: results of an international survey. National Multiple Sclerosis Society (USA) Advisory Committee on Clinical Trials of New Agents in Multiple Sclerosis. Neurology 46: 907-911

MacMicking J, Xie QW, Nathan C (1997) Nitric oxide and macrophage function. Annu Rev Immunol 15: 323-350

Mantovani A, Sica A, Sozzani S, Allavena P, Vecchi A, Locati M (2004b) The chemokine system in diverse forms of macrophage activation and polarization. Trends Immunol 25: 677-686

Mantovani A, Sica A, Sozzani S, Allavena P, Vecchi A, Locati M (2004a) The chemokine system in diverse forms of macrophage activation and polarization. Trends Immunol 25: 677-686

Martinez FO, Gordon S, Locati M, Mantovani A (2006) Transcriptional profiling of the human monocyte-to-macrophage differentiation and polarization: new molecules and patterns of gene expression. J Immunol 177: 7303-7311

Martinez FO, Sica A, Mantovani A, Locati M (2008) Macrophage activation and polarization. Front Biosci 13: 453-461

Matsushima GK, Morell P (2001) The neurotoxicant, cuprizone, as a model to study demyelination and remyelination in the central nervous system. Brain Pathol 11: 107-116

McDonald WI, Compston A, Edan G, Goodkin D, Hartung HP, Lublin FD, McFarland HF, Paty DW, Polman CH, Reingold SC, Sandberg-Wollheim M, Sibley W, Thompson A, van den NS, Weinshenker BY, Wolinsky JS (2001) Recommended diagnostic criteria for multiple sclerosis: guidelines from the International Panel on the diagnosis of multiple sclerosis. Ann Neurol 50: 121-127

Medzhitov R, Janeway CA, Jr. (2002) Decoding the patterns of self and nonself by the innate immune system. Science 296: 298-300

Mikita J, Dubourdieu-Cassagno N, Deloire MS, Vekris A, Biran M, Raffard G, Brochet B, Canron MH, Franconi JM, Boiziau C, Petry KG (2011) Altered M1/M2 activation 
patterns of monocytes in severe relapsing experimental rat model of multiple sclerosis. Amelioration of clinical status by M2 activated monocyte administration. Mult Scler 17: 2-15

Miller DH, Grossman RI, Reingold SC, McFarland HF (1998) The role of magnetic resonance techniques in understanding and managing multiple sclerosis. Brain 121 ( $\mathrm{Pt} 1$ ): 3-24

Miron VE, Ludwin SK, Darlington PJ, Jarjour AA, Soliven B, Kennedy TE, Antel JP (2010) Fingolimod (FTY720) enhances remyelination following demyelination of organotypic cerebellar slices. Am J Pathol 176: 2682-2694

Modolell M, Corraliza IM, Link F, Soler G, Eichmann K (1995) Reciprocal regulation of the nitric oxide synthase/arginase balance in mouse bone marrow-derived macrophages by TH1 and TH2 cytokines. Eur J Immunol 25: 1101-1104

Mosser DM (2003) The many faces of macrophage activation. J Leukoc Biol 73: 209-212

Mosser DM, Edwards JP (2008) Exploring the full spectrum of macrophage activation. Nat Rev Immunol 8: 958-969

Nathan C (2008) Metchnikoff's Legacy in 2008. Nat Immunol 9: 695-698

Nathan C, Shiloh MU (2000) Reactive oxygen and nitrogen intermediates in the relationship between mammalian hosts and microbial pathogens. Proc Natl Acad Sci U S A 97: 8841-8848

Nave KA (1994) Neurological mouse mutants and the genes of myelin. J Neurosci Res 38: 607612

Nesbit GM, Forbes GS, Scheithauer BW, Okazaki H, Rodriguez M (1991) Multiple sclerosis: histopathologic and MR and/or CT correlation in 37 cases at biopsy and three cases at autopsy. Radiology 180: 467-474

Newman TA, Woolley ST, Hughes PM, Sibson NR, Anthony DC, Perry VH (2001) T-celland macrophage-mediated axon damage in the absence of a CNS-specific immune response: involvement of metalloproteinases. Brain 124: 2203-2214

Nielsen JM, Korteweg T, Barkhof F, Uitdehaag BM, Polman CH (2005) Overdiagnosis of multiple sclerosis and magnetic resonance imaging criteria. Ann Neurol 58: 781-783

O'Shea JJ, Murray PJ (2008) Cytokine signaling modules in inflammatory responses. Immunity 28: 477-487

Palin K, Cunningham C, Forse P, Perry VH, Platt N (2008) Systemic inflammation switches the inflammatory cytokine profile in CNS Wallerian degeneration. Neurobiol Dis 30: 19-29

Paolino E, Fainardi E, Ruppi P, Tola MR, Govoni V, Casetta I, Monetti VC, Granieri E, Carreras M (1996) A prospective study on the predictive value of CSF oligoclonal bands and MRI in acute isolated neurological syndromes for subsequent progression to multiple sclerosis. J Neurol Neurosurg Psychiatry 60: 572-575

Pardo B, Honegger P (2000) Differentiation of rat striatal embryonic stem cells in vitro: monolayer culture vs. three-dimensional coculture with differentiated brain cells. $J$ Neurosci Res 59: 504-512

Polman CH, Reingold SC, Banwell B, Clanet M, Cohen JA, Filippi M, Fujihara K, Havrdova E, Hutchinson M, Kappos L, Lublin FD, Montalban X, O'Connor P, SandbergWollheim M, Thompson AJ, Waubant E, Weinshenker B, Wolinsky JS (2011) Diagnostic criteria for multiple sclerosis: 2010 revisions to the McDonald criteria. Ann Neurol 69: 292-302

Polman CH, Reingold SC, Edan G, Filippi M, Hartung HP, Kappos L, Lublin FD, Metz LM, McFarland HF, O'Connor PW, Sandberg-Wollheim M, Thompson AJ, Weinshenker BG, Wolinsky JS (2005) Diagnostic criteria for multiple sclerosis: 2005 revisions to the "McDonald Criteria". Ann Neurol 58: 840-846 
Popovich PG, Guan Z, Wei P, Huitinga I, van RN, Stokes BT (1999) Depletion of hematogenous macrophages promotes partial hindlimb recovery and neuroanatomical repair after experimental spinal cord injury. Exp Neurol 158: 351365

Prineas JW, Barnard RO, Kwon EE, Sharer LR, Cho ES (1993) Multiple sclerosis: remyelination of nascent lesions. Ann Neurol 33: 137-151

Prineas JW, Connell F (1979) Remyelination in multiple sclerosis. Ann Neurol 5: 22-31

Pugliatti M, Sotgiu S, Rosati G (2002) The worldwide prevalence of multiple sclerosis. Clin Neurol Neurosurg 104: 182-191

Raine CS, Wu E (1993) Multiple sclerosis: remyelination in acute lesions. J Neuropathol Exp Neurol 52: 199-204

Rapalino O, Lazarov-Spiegler O, Agranov E, Velan GJ, Yoles E, Fraidakis M, Solomon A, Gepstein R, Katz A, Belkin M, Hadani M, Schwartz M (1998) Implantation of stimulated homologous macrophages results in partial recovery of paraplegic rats. Nat Med 4: 814-821

Rodriguez M, Lucchinetti CF (1999) Is apoptotic death of the oligodendrocyte a critical event in the pathogenesis of multiple sclerosis?. Neurology 53: 1615-1616

Romieu-Mourez R, Solis M, Nardin A, Goubau D, Baron-Bodo V, Lin R, Massie B, Salcedo M, Hiscott J (2006) Distinct roles for IFN regulatory factor (IRF)-3 and IRF-7 in the activation of antitumor properties of human macrophages. Cancer Res 66: 1057610585

Shechter R, London A, Varol C, Raposo C, Cusimano M, Yovel G, Rolls A, Mack M, Pluchino S, Martino G, Jung S, Schwartz M (2009) Infiltrating blood-derived macrophages are vital cells playing an anti-inflammatory role in recovery from spinal cord injury in mice. PLoS Med 6: e1000113

Smith KJ, Kapoor R, Hall SM, Davies M (2001) Electrically active axons degenerate when exposed to nitric oxide. Ann Neurol 49: 470-476

Song E, Ouyang N, Horbelt M, Antus B, Wang M, Exton MS (2000) Influence of alternatively and classically activated macrophages on fibrogenic activities of human fibroblasts. Cell Immunol 204: 19-28

Stein M, Keshav S, Harris N, Gordon S (1992) Interleukin 4 potently enhances murine macrophage mannose receptor activity: a marker of alternative immunologic macrophage activation. J Exp Med 176: 287-292

Stirling DP, Khodarahmi K, Liu J, McPhail LT, McBride CB, Steeves JD, Ramer MS, Tetzlaff W (2004) Minocycline treatment reduces delayed oligodendrocyte death, attenuates axonal dieback, and improves functional outcome after spinal cord injury. J Neurosci 24: 2182-2190

Takeda K, Akira S (2005) Toll-like receptors in innate immunity. Int Immunol 17: 1-14

Teunissen CE, Dijkstra CD, Jasperse B, Barkhof F, Vanderstichele H, Vanmechelen E, Polman CH, Bo L (2006) Growth-associated protein 43 in lesions and cerebrospinal fluid in multiple sclerosis. Neuropathol Appl Neurobiol 32: 318-331

Teunissen CE, Iacobaeus E, Khademi M, Brundin L, Norgren N, Koel-Simmelink MJ, Schepens M, Bouwman F, Twaalfhoven HA, Blom HJ, Jakobs C, Dijkstra CD (2009) Combination of CSF $\mathrm{N}$-acetylaspartate and neurofilaments in multiple sclerosis. Neurology 72: 1322-1329

Teunissen CE, Koel-Simmelink MJ, Pham TV, Knol JC, Khalil M, Trentini A, Killestein J, Nielsen J, Vrenken H, Popescu V, Dijkstra CD, Jimenez CR (2011) Identification of biomarkers for diagnosis and progression of MS by MALDI-TOF mass spectrometry. Mult Scler 17: 838-850 
Teunissen CE, Steinbusch HW, Markerink-van Ittersum M., de Bruijn C., Axer H, de Vente J. (2000) Whole brain spheroid cultures as a model to study the development of nitric oxide synthase-guanylate cyclase signal transduction. Brain Res Dev Brain Res 125: 99-115

Trapp BD, Peterson J, Ransohoff RM, Rudick R, Mork S, Bo L (1998) Axonal transection in the lesions of multiple sclerosis. N Engl J Med 338: 278-285

Van den Bossche J., Bogaert P, Van Hengel J, Guerin CJ, Berx G, Movahedi K, Van den Bergh R., Pereira-Fernandes A, Geuns JM, Pircher H, Dorny P, Grooten J, De Baetselier P., Van Ginderachter JA (2009) Alternatively activated macrophages engage in homotypic and heterotypic interactions through IL-4 and polyamineinduced E-cadherin/catenin complexes. Blood 114: 4664-4674

van der Goes A., Boorsma W, Hoekstra K, Montagne L, De Groot CJ, Dijkstra CD (2005) Determination of the sequential degradation of myelin proteins by macrophages. $J$ Neuroimmunol 161: 12-20

van der Valk, De Groot CJ (2000) Staging of multiple sclerosis (MS) lesions: pathology of the time frame of MS. Neuropathol Appl Neurobiol 26: 2-10

Vereyken EJ, Fluitsma DM, Bolijn MJ, Dijkstra CD, Teunissen CE (2009) An in vitro model for de- and remyelination using lysophosphatidyl choline in rodent whole brain spheroid cultures. Glia 57: 1326-1340

Vereyken EJ, Heijnen PD, Baron W, de Vries EH, Dijkstra CD, Teunissen CE (2011) Classically and alternatively activated bone marrow derived macrophages differ in cytoskeletal functions and migration towards specific CNS cell types. J Neuroinflammation 8: 58

Weber MS, Prod'homme T, Youssef S, Dunn SE, Rundle CD, Lee L, Patarroyo JC, Stuve O, Sobel RA, Steinman L, Zamvil SS (2007) Type II monocytes modulate T cellmediated central nervous system autoimmune disease. Nat Med 13: 935-943

Wolswijk G (2000) Oligodendrocyte survival, loss and birth in lesions of chronic-stage multiple sclerosis. Brain 123 ( Pt 1): 105-115

Wolswijk G (2002) Oligodendrocyte precursor cells in the demyelinated multiple sclerosis spinal cord. Brain 125: 338-349

Woodruff RH, Franklin RJ (1999) Demyelination and remyelination of the caudal cerebellar peduncle of adult rats following stereotaxic injections of lysolecithin, ethidium bromide, and complement/anti-galactocerebroside: a comparative study. Glia 25: 216-228

Zeyda M, Farmer D, Todoric J, Aszmann O, Speiser M, Gyori G, Zlabinger GJ, Stulnig TM (2007) Human adipose tissue macrophages are of an anti-inflammatory phenotype but capable of excessive pro-inflammatory mediator production. Int J Obes (Lond) 31: 1420-1428

Zhang X, Mosser DM (2008) Macrophage activation by endogenous danger signals. J Pathol 214: $161-178$

Zhang Z, Zhang ZY, Schluesener HJ (2009) Compound A, a plant origin ligand of glucocorticoid receptors, increases regulatory $\mathrm{T}$ cells and M2 macrophages to attenuate experimental autoimmune neuritis with reduced side effects. J Immunol 183: 3081-3091

Zheng D, Wang Y, Cao Q, Lee VW, Zheng G, Sun Y, Tan TK, Wang Y, Alexander SI, Harris DC (2011) Transfused macrophages ameliorate pancreatic and renal injury in murine diabetes mellitus. Nephron Exp Nephrol 118: e87-e99

Ziemann U, Wahl M, Hattingen E, Tumani H (2011) Development of biomarkers for multiple sclerosis as a neurodegenerative disorder. Prog Neurobiol 


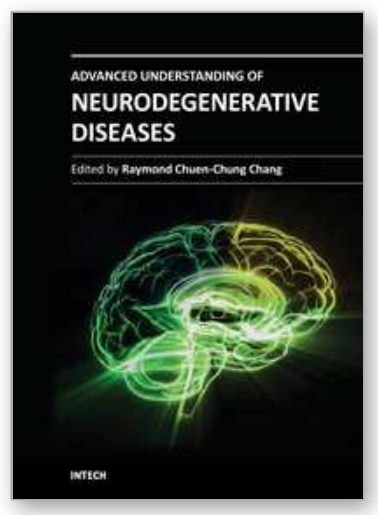

\author{
Advanced Understanding of Neurodegenerative Diseases \\ Edited by Dr Raymond Chuen-Chung Chang
}

ISBN 978-953-307-529-7

Hard cover, 442 pages

Publisher InTech

Published online 16, December, 2011

Published in print edition December, 2011

Advanced Understanding of Neurodegenerative Diseases focuses on different types of diseases, including Alzheimer's disease, frontotemporal dementia, different tauopathies, Parkinson's disease, prion disease, motor neuron diseases such as multiple sclerosis and spinal muscular atrophy. This book provides a clear explanation of different neurodegenerative diseases with new concepts of understand the etiology, pathological mechanisms, drug screening methodology and new therapeutic interventions. Other chapters discuss how hormones and health food supplements affect disease progression of neurodegenerative diseases. From a more technical point of view, some chapters deal with the aggregation of prion proteins in prion diseases. An additional chapter to discuss application of stem cells. This book is suitable for different readers: college students can use it as a textbook; researchers in academic institutions and pharmaceutical companies can take it as updated research information; health care professionals can take it as a reference book, even patients' families, relatives and friends can take it as a good basis to understand neurodegenerative diseases.

\title{
How to reference
}

In order to correctly reference this scholarly work, feel free to copy and paste the following:

\section{E.J.F. Vereyken, C.D. Dijkstra and C.E. Teunissen (2011). Modelling Multiple Sclerosis In Vitro and the} Influence of Activated Macrophages, Advanced Understanding of Neurodegenerative Diseases, Dr Raymond Chuen-Chung Chang (Ed.), ISBN: 978-953-307-529-7, InTech, Available from:

http://www.intechopen.com/books/advanced-understanding-of-neurodegenerative-diseases/modellingmultiple-sclerosis-in-vitro-and-the-influence-of-activated-macrophages

\section{INTECH}

open science | open minds

\section{InTech Europe}

University Campus STeP Ri

Slavka Krautzeka 83/A

51000 Rijeka, Croatia

Phone: +385 (51) 770447

Fax: +385 (51) 686166

www.intechopen.com

\section{InTech China}

Unit 405, Office Block, Hotel Equatorial Shanghai

No.65, Yan An Road (West), Shanghai, 200040, China

中国上海市延安西路65号上海国际贵都大饭店办公楼405单元

Phone: +86-21-62489820

Fax: +86-21-62489821 
(C) 2011 The Author(s). Licensee IntechOpen. This is an open access article distributed under the terms of the Creative Commons Attribution 3.0 License, which permits unrestricted use, distribution, and reproduction in any medium, provided the original work is properly cited. 